Light as a positive situational cue at work: Satisfaction with light relates to judgments of other's warmth and competence

\author{
Olga Kombeiz \\ Loughborough University, \\ Loughborough, United Kingdom
}

Erik Dietl

Loughborough University,

Loughborough, United Kingdom

Manuscript accepted for publication in

Ergonomics - April 2019

The manuscript may not exactly replicate the final version published in the journal. It is not the copy of record. The final article will be available, upon publication, via its DOI. 
Light as a positive situational cue at work: Satisfaction with light relates to judgments of other's warmth and competence

\section{Olga Kombeiz* and Erik Dietl}

School of Business and Economics, Loughborough University, United Kingdom

*Email: o.kombeiz@ lboro.ac.uk, Phone: +44 (0) 1509228847

Olga Kombeiz is a teaching fellow in Human Resource Management and Organizational Behaviour at Loughborough University, UK. Her research interests include the influence of the work environment on performance, perception and behaviour.

Erik Dietl is a lecturer in Human Resource Management and Organizational Behaviour at Loughborough University, UK. His research focuses on work design, leadership, motivation, personality, and implicit cognition at work.

Wordcount: 5.889

\section{Acknowledgements}

This paper is partially based on the first author's doctoral thesis (Kombeiz 2016) and supported by “Gips-Schüle-Stiftung” (https://www.gips-schuele-stiftung.de). The authors would like to express their gratitude to Anna Steidle for her contribution to the design of the laboratory study and for insightful comments on a previous draft of this paper. We also thank Konrad Senf for proofreading an earlier version of this paper and we thank Anne Jülicher, Hanna Wikström, and Nicole Wieland for their help in collecting data for the laboratory study. 


\title{
Light as a positive situational cue at work: Satisfaction with light relates to judgments of other's warmth and competence
}

\begin{abstract}
Workplace illumination is known to impact mood, performance and decision making. Based on the idea that positive feelings associated with light might influence social judgments in workplaces, we propose that satisfaction with light as a specific affective response to light would lead to positive judgments of other individuals. In a laboratory experiment $(\mathrm{N}=164)$, participants assessed their satisfaction with light and rated other person's faces on warmth and competence. Results showed that satisfaction with light positively influenced judgment of others. We replicated the positive relation between satisfaction with light and social judgments in a field study with employees $(\mathrm{N}=176)$. These findings highlight the importance of satisfaction with light for social judgment in workplaces. We discuss theoretical contributions and practical implications concerning the design of settings involving the evaluation of other individuals.
\end{abstract}

Practitioner Summary: The design of work settings where the evaluation of others takes place is an important topic. A laboratory experiment and a field study demonstrate that satisfaction with workplace illumination influences judgments of others. The results provide interesting possibilities for the design of work settings that involve the evaluation of others.

Keywords: light, satisfaction with light, social judgment, warmth, competence

\section{Introduction}

Workplace illumination is one of the important aspects that determine employee's productivity and well-being (Baron, Rea, and Daniels 1992; Dianat et al. 2013; Juslén, Wouters, and Tenner 2007; Küller and Laike 1998). Previous research of non-visual effects of light focused on negotiation behaviour, mental performance, and creativity to understand human functioning in work contexts (Baron, Rea, and Daniels 1992; Kombeiz, Steidle, and Dietl 2017, Kombeiz and Steidle 2018; Leichtfried et al. 2015). However, little research has examined whether satisfaction with light may 
impact social perception and the evaluation of others. This topic is highly relevant because the findings can contribute to the design of work environments involving the evaluation of others that may have far-reaching consequences. For instance, in hiring, leader selection, or voting decisions, social judgments may be influenced by the first impression of a person's physical appearance (Dietl, Rule, and Blickle 2018; Riggio and Throckmorton 1988; Todorov et al. 2005), by one's mood (Baron 1987), or by situational cues such as the presence of others (Rowe 1967) and the physical environment (Baron, Rea, and Daniels 1992). Moreover, a recent review highlighted the physical environment as a source of affective responses that impact behaviours and attitudes of office workers (Ashkanasy, Ayoko, and Jehn 2014).

Both the positive affect theory (Isen and Baron 1991) and the theory of environmentally-induced positive affect (Baron 1990) suggest that positive affect is the underlying process in the relation between the physical environment and employees' well-being and work-related behaviours. Research that built on these theories revealed that light had an effect on work performance via room appraisal, aesthetic judgments and mood (Newsham and Veitch 2001; Veitch et al. 2008; Veitch, Stokkermans, and Newsham 2013). However, the idea of environmentally-induced positive affect as the underlying process in the relation between light and social judgment found only indirect support (Baron, Rea, and Daniels 1992). Moreover, in contrast to Baron and colleagues' study (1992), other research did not find direct or indirect effects of light on the evaluation of persons (Boyce et al. 2003; Knez and Enmarker 1998; Veitch and Newsham 1998). Taken together, research revealed inconsistent results concerning the question whether affective processes mediate the effects of light on social judgment. Furthermore, existing studies are limited because they focused on assessments of general affective state (i.e., negative and positive affect), and used very few stimuli for 
the social judgment task (Knez and Enmarker 1998). To clarify these inconsistent findings and to overcome prior limitations, the present research focuses on specific instead of general affective states. We argue that satisfaction with light is a specific affective state associated with light and propose that satisfaction with light would influence the valence of social judgment regarding two basic dimensions, warmth and competence (Fiske, Cuddy, and Glick 2007).

Our research offers several contributions. First, we directly examine whether environmentally-induced satisfaction as a specific affective state leads to positive social judgment. In particular, we propose that satisfaction with light, which represents an affective response to workplace illumination, is positively associated with judgments of other's warmth and competence. The importance of investigating satisfaction with light and its positive effects was highlighted recently (van Duijnhoven et al. 2017). Second, the results could allow practical implications for the design of environments in which the judgment of others is important (e.g., rooms for job interviews).

\subsection{Satisfaction with Light as a Specific Affective State}

Satisfaction with light is an individual reaction to lighting characteristics and describes a subjective level of comfort with light that includes a cognitive component because of conscious or unconscious appraisals and preferences of lighting (Veitch et al. 2008), and an affective component that relates to how individuals feel in the room (Veitch and Newsham 1998). Both components are frequently used to describe subjective satisfaction with a lighting condition (e.g., Veitch and Newsham 1998, 2000). Satisfaction with light describes a psychological effect of light (Flynn 1992), an affective state, that is subjective and may well differ between individuals. Consequently, positive evaluations of a lighting condition could serve as an indicator of environmentally-induced satisfaction. 
Previous research indicates that environmental conditions, for instance, some kinds of music (May and Hamilton 1980), pleasant scents (Baron 1990; Sona, Dietl, and Steidle 2018), and pleasant room temperature (Bowman, Giuliani, and Minge 1981) may elicit positive affective states. Lighting is another important characteristic of indoor environments that may induce positive affect. Up to now, there are mixed findings concerning this proposition (e.g., Küller et al. 2006; Zhu et al. 2019) and several studies found only indirect support for the effect of lighting on affective states (e.g., Baron, Rea, and Daniels 1992; Boyce et al. 2006a; Veitch et al. 2008). For instance, individuals who are satisfied with the lighting evaluate the room as more attractive, which in turn leads to positive mood (Veitch et al. 2008). The lack of reported direct effects on general levels of affect or mood may be explained by the variations in lighting that have been used in past laboratory studies, which might have been too subtle to influence general affect (e.g., when measured with the PANAS scales, Baron, Rea, and Daniels 1992). Yet, satisfaction with light as a specific affective state associated with light could be detected even if there were no effects on general affective state. In line with this idea, recent studies showed that lighting conditions directly influenced their appraisal and only indirectly that of mood (Boyce et al. 2006a; Veitch, Stokkermans, and Newsham 2013). Therefore, we integrated components of previous studies that focused on: light quality as a sign of satisfaction with light, preferences for specific lighting conditions and affect (Baron, Rea, and Daniels 1992; Boyce et al. 2006a; Veitch et al. 2008), and examined satisfaction with light as an indicator of environmentally-induced satisfaction. Previous studies support this idea, as satisfaction with environmental conditions (e.g., light) has been well predicted by lighting conditions (Veitch et al. 2008; Veitch, Stokkermans, and Newsham 2013). 


\subsection{Social Judgment}

Social perception can be defined as evaluation or judgment of different characteristics of others, and how individuals shape impressions about others using available information, such as physical appearance, verbal and nonverbal communication, and behaviour (Niedenthal and Halberstadt 2004). In the work context, two basic dimensions underlie social judgment and despite varying definitions they refer to such attributes as warmth/communality and competence/agency (Fiske, Cuddy, and Glick 2007; Judd et al. 2005; Imhoff and Koch 2017). Accordingly, warmth reflects traits such as friendliness, helpfulness, and trustworthiness, whereas competence is related to perceived ability, skill, efficacy, and intelligence. Both dimensions are fundamental to social perception and are equally important in impression formation (Fiske, Cuddy, and Glick 2007; Nauts et al. 2014).

There are different conceptions about the relationship between warmth and competence. In their research on stereotyping of groups, Fiske et al. (2002) proposed and found an orthogonal relationship, but Imhoff and Koch (2017) reported a curvilinear relation between the two dimensions. Other researchers found evidence for a positive correlation between warmth and competence (e.g., Abele and Wojciszke 2007; Durante et al. 2013; Rule and Ambady 2011). In particular, when judging individuals (Rule and Ambady 2010; 2011) rather than groups (Fiske, Cuddy, and Glick 2007) a positive relationship between both dimensions has been found. This positive relationship can be explained by the motivation to generalize positive and negative evaluations of individuals (halo and horns effect; Dion, Berscheid, and Walster 1972). As the present study focused on judgments of individuals, we expected that the valence of the judgment is central, and therefore, we expect similar effects of satisfaction with light on the two dimensions. 


\subsection{Affective States and Social Judgment}

Social perception in general and person perception in particular, may depend on an observer's actual affective state (Forgas 1995; Forgas and George 2001). Even mild shifts in affective states can influence work-related perception and behaviour (Forgas and George 2001; Park, Sims, and Motowidlo 1986). For instance, affective states have been shown to influence performance appraisals and managers' reactions to poor subordinate performance (Cardy and Dobbins 1986; Dobbins and Russell 1986). Such mood-based distortions in person perception occur because of information processing as a consequence of mood (Forgas and George 2001). Accordingly, perceiving a person is an act of categorization (Bruner 1957), and affective states bias person perception by distorting the spontaneous associations and interpretations we make (Clark and Isen 1982). In line with this idea, individuals in a positive mood rate others as more attractive, competent, and likable (Clark and Waddell 1983; Forgas and George 2001). Similarly, inducing positive affect leads to positive evaluations of job candidates (Baron 1987; Baron, Rea, and Daniels 1992). Dim light led to positive ratings of a fictitious employee (Baron, Rea, and Daniels 1992) and an unexpected receipt of a gift was previously shown to induce positive affect (Isen 1987). Baron, Rea, and Daniels (1992) interpreted this analogy as support for the notion of environmentally-induced positive affect. Thus, mild shifts in affective states may be created by situational and environmental factors, such as exposure to pleasant or unpleasant films (Arkes, Herren, and Isen 1988), receipt of a small gift (Isen 1987), or pleasant artificial scents (Baron 1990) and light (Knez 1995; Küller et al. 2006). Most procedures (e.g., a gift; Isen 1987) are rather unusual and more obvious in the working context than ordinary environmental conditions, such as lighting (Baron, Rea, and Daniels 1992), which may be subtler in triggering positive affect. 
However, previous research showed mixed findings for effects of light on affect (Baron, Rea, and Daniels 1992; Knez 1995; Veitch et al. 2008). Whereas some studies found an effect of light on affective states or mood (e.g. Knez 1995; Knez and Enmarker 1998), in other studies, light did not have a direct effect on affect, but on light appraisals such as aesthetic judgments that can be interpreted as satisfaction with light (Baron, Rea, and Daniels 1992; Veitch et al. 2008). Moreover, a recent study found that specific affective responses to light did not lead to changes in general affective state (de Vries et al. 2018). Thus, based on these recent findings and Baron's (1990) notion of environmentally-induced positive affect, we propose that satisfaction with light would better describe a specific affective state associated with an environmental condition (i.e., light). As satisfaction with light represents the positive affect associated with light, we expected that this positive feeling would transfer to the first impressions of unknown faces, and therefore be responsible for positive judgments of warmth and competence. Accordingly, feelings can be conceptualized as information that individuals use to form judgments about others. Although the content of this affective information (i.e., affect associated with light) differs from the object that has to be judged (i.e., an unknown face), the feelings are used as signals that provide available and reliable information for making judgments (Bless 2002; Clore et al. 2001). Thus, affectively loaded information exerts an influence on a person's judgmental processes colouring the outcome in a feeling-congruent way (Forgas 1995). Hence, feeling satisfied with the lighting would lead to feeling-congruent thoughts and judgments referring to a match in valence (Mayer et al. 1992) between the actual satisfaction with the one's environment and the judgment of others. In support of this idea, individuals frequently use feelings as information for making judgments (Forgas and George 2001; Greifeneder, Bless, and Pham 2011). Taken together, we hypothesize that satisfaction with light as a specific 
affective response would have a positive effect on social judgment. More specifically, satisfaction with light would be positively associated with judgments of warmth (Hypothesis 1) and with judgments of competence (Hypothesis 2).

\subsection{Overview of the Present Research}

We use two studies to test our hypotheses. We employed a comprehensive approach by, first, manipulating light characteristics in the laboratory to elicit a broad range of satisfaction with light responses and investigating the impact of satisfaction with light on social judgment (Study 1). Then, in Study 2 we examined naturally occurring variations of the phenomena in the field. Study 2, conducted in the context of real work environments, tested how employee's satisfaction with light relates to their social judgments of others. The aim was to obtain both internally valid (experiment) and externally valid (field survey) findings. Finally, we also examined an alternative model in which general affective state (positive mood) mediates the positive relationships between specific affective responses (i.e., satisfaction with light) and social judgment as originally proposed by Baron (1990), Isen and Baron (1991), and applied by Newsham and Veitch (2001), Veitch, Stokkermans, and Newsham (2013) and Veitch et al. (2008) in the area of light's effects on performance and well-being.

\section{Study 1}

\subsection{Method}

\subsubsection{Ethical statement}

The ethical principles as formulated in the WMA Declaration of Helsinki guided our research project. The experimenter informed the participants about the procedure of the study and pointed out that participation is voluntary, anonymous, and can be cancelled at any time. The study began after each participant provided verbal consent. 


\subsubsection{Participants}

One hundred and sixty-six German students were recruited via university mailing lists and took part in exchange for course credit or for a payment of $€ 15$. Two persons were excluded from the analysis because they indicated that they did not understand some instructions. Data of 85 females and 79 males $(N=164$; mean age $=$ 23.62 years; $S D=5.52$ ) were used for the analyses. Most of the participants were enrolled in studies of economics $(N=51)$, aerospace engineering $(N=38)$, mechanical engineering $(N=11)$, and civil engineering $(N=11)$ at the University of Stuttgart in Germany and were on average in their third year.

\subsubsection{Procedure}

The experiment was conducted at Fraunhofer Institute for Building Physics in Stuttgart, Germany, as part of a larger research project in a laboratory that was designed for office work ${ }^{2}$. The room contained regular office furniture: two desks and chairs for participants and one for the experimenter, a monitor and a keyboard on each desk. The desk and monitor were positioned between the luminaires to avoid reflections and glare for the sitting participants (see Figure 1). The walls and the ceiling were white, and the carpeted floor was dark grey. The room $(5.10 \times 3.50$ meters and 3.00 meters high $)$ was equipped with protection from the daylight. The light was offered through 3 pendantmounted ceiling LED-based luminaires with an average of $21 \%$ indirect light, each 116 $\mathrm{cm}$ long and $8.5 \mathrm{~cm}$ wide. To elicit a broad range of satisfaction with light responses, the luminaires were set to create either bright (1500 lx) or $\operatorname{dim}(150 \mathrm{~lx})$ direct-indirect lighting, combined with either cold white $(5500 \mathrm{~K})$ or warm white $(2500 \mathrm{~K})$ colour temperature. The horizontal and vertical measures of illuminance and colour temperature were taken when the computer displays were on, such that the overall illuminance and colour temperature are products of both light sources. To assess the 
contribution of light coming from the computer display, we measured the vertical illuminance at a height of 1.20 metre, which approximately corresponds to the sight of a sitting person and is in front of the computer display (see Table 1 for lighting measures). We balanced the time of day between the lighting conditions: After each session, the lighting conditions were changed to ensure that each lighting condition was used approximately equally often in the morning and afternoon hours.

The participants were randomly assigned to one of the four lighting conditions which were already present upon arrival. They were tested up to two at a time in the laboratory at a computer, approximately $60 \mathrm{~cm}$ from the screen facing the wall. Therefore, the participants could not see each other nor the experimenter, which should ensure that presence of a second person did not impact the results. The experiment lasted for one hour and $15 \mathrm{~min}$ and consisted of different tasks on the computer. After getting into the laboratory, participants first answered questions related to the present study, i.e., they judged 6 pictures on warmth and competence. Other tasks on the computer followed but did not relate to the present study. The room temperature was held constant $\left(23^{\circ} \mathrm{C}\right)$ using an air conditioning system. The laboratory had noise isolation. Thus, all physical features other than light were held constant.

\subsubsection{Material}

\subsubsection{Satisfaction with light}

Satisfaction with light was assessed with two items on a seven-point Likert-type scale (1: strongly disagree -7 : strongly agree; $\alpha=.86$ ). This scale is based on two validated one-item measures of satisfaction with light: the lighting subscale of the environmental satisfaction survey (Boubekri and Haghighat 1993) and the affective component of lighting quality scale by Veitch and Newsham (2000). Both measures have been frequently employed in environmental psychology (Boubekri 1995; Steidle 
and Werth 2013; Veitch et al. 2003; 2008). To increase reliability, we used both items: "The lighting is pleasant" and "I am satisfied with the lighting condition".

\subsubsection{Positive mood}

To address the alternative explanation with general affective state as a mediator (e.g., Baron, Rea, and Daniels 1992), we assessed positive mood using Nitsch's fouritem Affective State Scale ( $\alpha=.89$; Nitsch 1976). Participants rated how they felt at the moment (cheerful, happy, joyful, lively) on a nine-point Likert-type scale (1: strongly disagree - 9: strongly agree).

\subsubsection{Judgments of warmth and competence}

In a pilot study $(N=30)$, participants rated pictures of 20 male and 19 female Caucasian persons from the Radboud Faces Database (RaFD, Langner et al. 2010), with neutral emotional expressions from a frontal view, on attractiveness, warmth, and competence. The database provides high-quality stimuli, created under strictly controlled conditions. All pictures were taken under the same luminance level and show female and male individuals with a straight gaze. From 39 pictures, we selected three pictures of female and three pictures of male persons for the main study that possessed medium levels of attractiveness, warmth, and competence.

In the main study, we assessed participants' judgments of warmth and competence of the six preselected pictures on a seven-point Likert-type scale (1: strongly disagree - 7: strongly agree). Based on previous studies (Fiske et al. 2002; North and Fiske 2014), three items were used to measure warmth (warm, friendly, trustworthy) and four items for the measure of competence (competent, intelligent, confident, assertive). Warmth and competence ratings were first averaged for each picture (all $\alpha s>.81$ for warmth and all $\alpha s>.77$ for competence) and then averaged 
across all pictures (warmth: $\alpha=.74$, competence: $\alpha=.71$ ) to create an aggregated warmth and competence score for each participant.

\subsubsection{Analytic Strategy}

To test the Hypotheses 1 and 2, we used correlations. We conducted OLS mediation analyses using a bias-corrected bootstrapping procedure with 10,000 bootstraps to test the alternative mediation hypotheses (Hayes 2013). This analysis uses a regression-based approach to mediation, allows the specification of three paths, the predictor $(\mathrm{X})$, outcome $(\mathrm{Y})$, and mediator $(\mathrm{M})$, and allows the examination of indirect effects, i.e. how the predictor affects the outcome via the mediator (Hayes 2013).

\subsection{Results}

\subsubsection{Hypothesis Testing}

Table 2 presents descriptive statistics and correlations of all variables. The lighting conditions produced a broad range of satisfaction with light scores $(M=4.34$, $S D=1.76$ ) ranging from 1 to 7 . As expected, satisfaction with light was positively related to judgments of warmth $(r=.22, p<.01)$ and competence $(r=.23, p<.01)$. Hence, hypotheses $\mathrm{H} 1$ and $\mathrm{H} 2$ were supported.

We used mediation analysis (Hayes 2013) to test the alternative model which proposes that positive mood mediates the positive relations between satisfaction with light and social judgement. Positive mood was unrelated to satisfaction with light $(r=$ $.04, p=.60)$, judgments of warmth $(r=.06, p=.44)$ and competence $(r=.04, p=.64)$. Consequently, the mediation analyses did not reveal significant indirect effects of satisfaction with light on judgments of warmth (indirect effect $=.001, S E=.004,95 \%$ CI $[-.003, .02]$, Table 3 , Model $1 \& 2$ ) and competence (indirect effect $=.001, S E=$ 
$.003,95 \%$ CI [-.003, .010], Table 3, Model $1 \& 3$ ) via positive mood. Therefore, the alternative explanation with positive mood as mediator was not supported.

\subsubsection{Supplementary Analyses}

Because previous research showed an impact of lighting on people's subjective judgments (Boyce and Cuttle 1990; Davis and Ginthner 1990; Fotios 2017) we explored whether the lighting conditions used in this study had an influence on satisfaction with light, positive mood and the judgments of warmth and competence. We conducted oneway ANOVAs with lighting condition (dim warm, bright warm, dim cold, bright cold) as independent variable. The results did not reveal any significant effects on satisfaction with light $(F(3,160)=1.81, p=.15)$, positive $\operatorname{mood}(F(3,160)=0.42, p=.74)$, judgments of warmth $(F(3,160)=0.75, p=.52)$ and judgments of competence $(F(3$, 160) $=1.79, p=.15)$.

\subsection{Discussion}

Study 1 established that satisfaction with light predicted judgments of warmth and competence in an office setting. The small to moderate correlation size (Cohen 1988) of these associations is consistent with prior studies that found small to moderate effect sizes in person perception (see Tskhay and Rule 2013 for a meta-analysis) and social cognition research (Richard et al. 2003). The small to moderate effect size is also in line with research on co-worker perceptions of employees (Dietl, Meurs and Blickle 2017). The additional explorative analysis suggests that individual satisfaction with light is more important than the lighting conditions themselves.

However, Study 1 also possessed limitations. Questions about external validity may arise because we used a student sample, and although we simulated a workplace office, the laboratory conditions did not consider context effects of real working 
environments such as daylight, room temperature or noise. Moreover, the lighting conditions had a large variation of illuminance and colour temperature that might not represent lighting conditions in real work environments (e.g., EN 12464 / ISO 8995 / ANSI/IESNA-RP-1-2012). To address these limitations, we tested whether employee's satisfaction with light predicts judgments of warmth and competence in real work environments (Study 2).

\section{Study 2}

In Study 2, we focused on a sample of employees in real work environments to increase the generalizability and external validity of our findings. We expected that satisfaction with light in the current room would be positively associated with judgments of warmth (Hypothesis 1) and competence (Hypothesis 2).

\subsection{Method}

\subsubsection{Ethical statement}

The ethical principles as formulated in the WMA Declaration of Helsinki guided our research project. We informed participants about the procedure of the study and pointed out that participation is voluntary, anonymous, and can be cancelled at any time. Participants provided online written informed consent.

\subsubsection{Participants and Procedure}

We recruited participants from Amazon's Mechanical Turk. Interested participants who are living in the United States and are full-time employees were directed to complete a short online questionnaire about person perception. The average time per assignment was 8 minutes with a payment between $\$ 0.43$ and $\$ 0.55$ for participation. We pre-screened 311 participants and recruited 187 of those who fulfilled 
our study requirements (i.e., full-time employees completing the survey at a place where they are usually working such as their office or home office). Following the recommendations by Meade and Craig (2012), we excluded seven participants who responded carelessly (i.e., those who failed the direct response measures (i.e., please select 'strongly agree' here). Moreover, we excluded three respondents who participated on this survey the second time and one person who had missing values. The final sample resulted in 176 full-time employees (51\% male) who meet all criteria. The participants' mean age was 34.53 years $(S D=9.24)$, their average work experience was 14.85 years $(S D=9.44)$, and they had worked in their current position for an average of 4.49 years $(S D=3.96) .42 .6 \%$ indicated having managerial or supervisory responsibilities for an average of 4.72 years $(S D=6.17)$. The participants worked on average 41.80 hours $(S D=5.48)$ each week and $86.3 \%$ worked at least half of the working time with others. Employees were asked to assess their satisfaction with light and then rated the same six pictures from Study 1 on warmth and competence.

\subsubsection{Material}

All instructions and scales were administered in English. The judgments of warmth and competence were assessed using the same instruments as in Study 1. The ratings were first averaged for each picture (all $\alpha s>.81$ for warmth and all $\alpha s>.74$ for competence) and then averaged across all pictures (warmth: $\alpha=.78$, competence: $\alpha=$ .82) to create an aggregated warmth and competence score for each participant. To increase the reliability, we used the two items of Study 1 and an additional item (Veitch and Newsham 2000) to measure satisfaction with light "The amount of light for the work that I am doing at the moment is appropriate" $(\alpha=.90)$. To measure positive mood, we used four items (cheerful, happy, joyful, lively) from the PANAS scale 
(Watson and Clark 1999), which corresponded to the four items of Nitsch's German Affective State Scale in Study $1(\alpha=.91)$.

\subsubsection{Analytic strategy}

We used the same analyses as in Study 1.

\subsection{Results and Discussion}

The descriptive statistics of Study 2 are presented in Table 4. Consistent with H1 and H2, employee's satisfaction with light was positively related to their judgments of warmth $(r=.19, p<.01)$ and competence $(r=.17, p<.05)$. The alternative model proposed that positive mood mediates the positive relationships between satisfaction with light and social judgment. In correlation analyses, positive mood was related to satisfaction with light $(r=.36, p<.01)$, judgments of warmth $(r=.17, p<.05)$, but unrelated to judgments of competence $(r=.14, p=.07)$. However, in regression analyses (Table 5) positive mood was unrelated to judgments of warmth $(b=.05, p=$ $.17)$ and competence $(b=.04, p=.27)$. Consequently, mediation analyses revealed that positive mood did not have significant indirect effects on judgments of warmth (indirect effect $=.02, S E=.02,95 \%$ CI $[-.01, .06]$, Table 5, Model $1 \& 2)$ and competence (indirect effect $=.018, S E=.017,95 \%$ CI $[-.014, .055]$, Table 5, Model $1 \& 3$ ) via positive mood. Again, the alternative explanation with positive mood as mediator was not supported.

The results of Study 2 showed once more that satisfaction with light was positively associated with social judgments. Moreover, the correlation size is consistent with Study 1 and research that found small to moderate effect sizes in the domain of person perception (Dietl, Meurs, and Blickle 2017; Tskhay and Rule 2013), and more generally field studies in applied psychology (Bosco et al. 2015). The similar pattern of 
results for satisfaction with light and social judgments across students in the laboratory and employees in real work environments suggests that our findings are generalizable.

Interestingly, in the field study, positive mood and satisfaction with light were related to a moderate degree, whereas they were unrelated in the laboratory study. This distinction might be explained by the variance of the satisfaction with light scores because of different lighting conditions. In the field study, participants could decide if they turn the light off, on, or dim it, whereas in the laboratory study, the lighting conditions were predefined. Because of the wide variation in individual preferences for light (e.g., Boyce et al. 2006b; Newsham and Veitch 2001), in the field study, participants could more easily adjust their lighting conditions, which might simultaneously facilitate satisfaction with light and positive mood. Future research could test this idea to examine these differences.

\section{General Discussion}

Given the importance of perception and evaluation of others in work contexts, which occurs automatically and may have far-reaching consequences in many situations, for instance in hiring decisions, investigating antecedents of persons' judgments is highly relevant.

The present research focused on satisfaction with light as an antecedent to judgments of other's warmth and competence. In a laboratory study, we found that satisfaction with light promoted positive person evaluations. In particular, satisfaction with lighting conditions led to increased warmth and competence judgments of individuals. In addition, a field study replicated these effects. Overall, we conclude that positive feelings associated with light may be transferred to positive social judgments of others. 
The present findings complement previous research on the effects of the physical environment - especially light - on social judgment in the work context and clarify previous mixed findings. One major contribution is the finding that satisfaction with light relates to judgment of others in work contexts. While at least one previous study showed that light may have an impact on the evaluation of others (Baron, Rea, and Daniels 1992), various other studies did not replicate this effect (Knez and Enmarker 1998; Boyce et al. 2006a). Moreover, Baron, Rea, and Daniels (1992) proposed but did not examine the underlying affective process. Thus, to our knowledge this is the first study showing that satisfaction with light acts as a specific affective response to light and leads to positive judgment of others. This finding is important as social perception - particularly judgments of warmth and competence - relates to a host of cognitive and behavioural consequences. For instance, warmth and competence judgments are essential for impression formation in general and the organizational context, specifically (Cuddy, Glick, and Beninger 2011; Fiske, Cuddy, and Glick 2007). The interpretation of one's own and others' behaviour, and the behaviour itself (Cuddy, Fiske, and Glick 2007; Wojciszke 1994) might be influenced by the judgment of these basic dimensions as well. Such positive social judgments are also known to influence well-being, social behaviour, productive work behaviour, and performance appraisals (Cuddy, Fiske, and Glick 2007; Taylor and Brown 1988).

The second important contribution of the present research is the empirical evidence for the notion of environmentally-induced satisfaction. In the area of lighting research, this idea has, to our knowledge, found direct support for the first time. Previous studies yielded a basis for this theoretical perspective, showing pleasant scents (Baron 1990) or room temperature (Bowman, Giuliani, and Minge 1981) to trigger positive affect. In contrast, the notion of environmentally-induced positive affect as a 
result of lighting conditions has found mixed (Küller et al. 2006, Zhu et al. 2019) or indirect support (Baron, Rea, and Daniels 1992). Apparently, the variations in lighting should be much bigger to produce reportable changes in general affect (Baron, Rea, and Daniels 1992; Boyce et al. 2003; de Vries et al. 2018), but can barely be found in real work situations because of lighting standards (e.g., EN 12464 / ISO 8995 / ANSI/IESNA-RP-1-2012). In contrast, satisfaction with light includes an affective component (Veitch and Newsham 1998) and is a good alternative to demonstrate shifts of affective state in different lighting conditions. Thus, based on this idea and the present results, we conclude that affective states closely associated with environmental conditions, for instance satisfaction with light or also room atmosphere could be more appropriate indicators of environmentally-induced satisfaction than general affective responses. This knowledge is important, as positive affective states have been shown to relate to a host of work-related behaviours besides social perception, such as helping behaviour, cooperation, and creative performance (Barry and Oliver 1996; Isen, Daubman, and Kowicki 1987; Salovey, Mayer, and Rosenhan 1991). However, the idea whether satisfaction with light would lead to these behavioural and performance outcomes needs to be examined in future research.

Finally, the field study complements the laboratory findings by showing the generalizability of lighting effects beyond the experimental conditions in the laboratory. Employee's satisfaction with light at their working place influenced their judgments of other's warmth and competence. Although no data about the lighting characteristics (illuminance level and colour temperature) were available, because of the international lighting standards (EN 12464 / ISO 8995 / ANSI/IESNA-RP-1-2012) the light in an office has to meet the required standards. Thus, it is very likely, that all employees were in a room with light that corresponds to the standard lighting. The concordance between 
the findings of Study 1 and 2 underscores the importance of subjective satisfaction with light for the evaluation of others in real work environments.

However, there are still open questions that should be addressed in future research. First, are the present results transferable to further domains of judgment of others? For instance, if short curriculum vitae in addition to photos of individuals' faces would not affect, decrease, strengthen, or eliminate the positive effect of light on perceived warmth and competence. Moreover, as we only investigated neutral emotional expressions, it would be interesting to learn whether judgments of warmth and competence would vary as a consequence of the interaction of satisfaction with light and different emotional expressions of presented faces. For instance, positive emotional expressions (e.g., a smile) have been shown to be associated with higher ratings of trustworthiness, affiliation, and dominance (Zebrowitz and Montepare 2008). Thus, positive judgments of these dimensions could eliminate the positive impact of satisfaction with light because of a ceiling effect. Furthermore, the current study only included the evaluation of Caucasian faces of young adults. Thus, at this stage of research, our findings cannot be transferred to individuals of other ethnic groups which calls for future research. Apart from these stimulus-based considerations, because of the close link between social judgment and stereotyping (Jussim 2012), examining shifts of stereotyping as a result of environmentally-induced positive affect could be a fruitful area for future research. Since individuals tend to stereotype and rely on heuristic processing more likely in positive mood (Chartrand, van Baaren, and Bargh 2006; Park and Banaji 2000), it could be speculated that satisfaction with light might increase stereotyping. Hence, possible negative effects of satisfaction with light on social judgment should be addressed in further research. 
The present study also provides practical implications for the design of environments in which the evaluation of others is important. For instance, offices where applications of job candidates will be evaluated, or rooms for job interviews could be equipped with lighting that is constant across evaluations of all job candidates. This would reduce possible bias in social perception because of lower satisfaction with a light. Similarly, the lighting in rooms for annual performance reviews should be standardized to ensure that staff evaluations are as objective as possible. Conversely, if employees are satisfied with light at their workplace, they could have an increased confidence in the competence of one's managers as well as more perceived warmth, which could in turn facilitate a more pleasant working atmosphere. Because of varying individual preferences for lighting conditions (Boyce at el. 2006b; Newsham and Veitch 2001), providing personal control of workplace illumination could lead to increased well-being and performance at work. Therefore, personal control of dimming or adjusting the warmth of the light according to subjective preferences could be an appropriate solution for most indoor environments.

\subsection{Conclusion}

The idea of environmentally-induced positive affect was proposed years ago (Baron 1990). Systematic consideration and investigation of its role in the lighting domain, however, has been lacking. Current results call for continued research of environmentally-induced satisfaction as a process underlying the relation between light and social judgment. Satisfaction with light as a specific affective response to light relates to perceived warmth and competence of others. Although there is still much to be understood about which lighting conditions lead to satisfaction with light, the present study suggests that satisfaction with light shapes judgments of others. 


\section{Endnotes}

1. A colour rendering index (CRI) refers to faithful colour appearance of an object in a test light compared to the standard light source.

2. The data presented in Study 1 were part of a broader data collection effort. However, we confirm that no substantive variable in this research report overlaps with our other research project. In addition, that study addresses a different research question using a different theoretical framework than the present study. 


\section{References}

Abele, A. E., and B. Wojciszke. 2007. "Agency and communion from the perspective of self versus others”. Journal of Personality and Social Psychology 93: 751-763. Doi: $10.1037 / 0022-3514.93 .5 .751$

Arkes, H. R., L. T. Herren, and A. M. Isen. 1988. "The role of potential loss in the influence of affect on risk-taking behavior." Organizational Behavior and Human Decision Processes 42: 181-191. doi:10.1016/0749-5978(88)90011-8

Ashkanasy, N. M., Ayoko, O. B., and K. A. Jehn. 2014. "Understanding the physical environment of work and employee behavior: An affective events perspective." Journal of Organizational Behavior 35: 1169-1184. https://doi.org/10.1002/job.1973

Baron, R. A. 1987. “Interviewer's Moods and Reactions to Job Applicants: The Influence of Affective States on Applied Social Judgments." Journal of Applied Social Psychology 17: 911-926. doi:10.1111/j.1559-1816.1987.tb00298.x

Baron, R. A. 1990. “Environmentally Induced Positive Affect: Its Impact on SelfEfficacy, Task Performance, Negotiation, and Conflict.” Journal of Applied Social Psychology 20: 368-384. doi:10.1111/j.1559-1816.1990.tb00417.x

Baron, R. A., M. S. Rea, and S. G. Daniels. 1992. "Effects of indoor lighting (illuminance and spectral distribution) on the performance of cognitive tasks and interpersonal behaviors: The potential mediating role of positive affect." Motivation and Emotion 16: 1-33. doi:10.1007/BF00996485

Barry, B., and R. L. Oliver. 1996. "Affect in dyadic negotiation: A model and propositions." Organizational Behavior and Human Decision Processes 67: 127-143. doi:10.1006/obhd.1996.0069 
Bless, H. 2002. "Where has the feeling gone? The signal function of affective states". Psychological Inquiry 13: 29-31.

Bosco, F. A., Aguinis, H., Singh, K., Field, J. G., and C.A. Pierce, C. 2015.

“Correlational effect size benchmarks". Journal of Applied Psychology 100: 431-449. doi: $10.1037 / \mathrm{a} 0038047$

Boubekri, M. 1995. "Appraisal of the lighting conditions in an office building: results of a survey." Indoor and Built Environment 4: 162-169.

doi:10.1177/1420326X9500400306

Boubekri, M., and F. Haghighat. 1993. "Windows and environmental satisfaction: A survey study of an office building." Indoor and Built Environment 2: 164-172. doi:10.1177/1420326X9300200305

Boyce P.R. and Cuttle C. 1990. Effect of correlated colour temperature on the perception of interiors and colour discrimination. Lighting Research and Technology 22: 19-36.

Boyce, P. R., J. A. Veitch, G. R. Newsham, M. Myer, and C. Hunter. 2003. Lighting quality and office work: A field simulation study (PNNL 14506). Richland, WA, USA: Pacific Northwest National Laboratory. doi:10.4224/20393390 Boyce, P. R., J. A. Veitch, G. R. Newsham, C. C. Jones, J. Heerwagen, M. Myer and C. M. Hunter. 2006a. "Lighting quality and office work: two field simulation experiments." Lighting Research and Technology 38: 191-223. doi:10.1191/13657828061rt161oa

Boyce, P. R., Veitch, J. A., Newsham, G. R., Jones, C. C., Heerwagen, J. H., Myer, M., 
and Hunter, C. M. 2006b. "Occupant use of switching and dimming controls in offices." Lighting Research and Technology 38: 358-378. doi: 10.1177/1477153506070994

Bowman, T. F., G. A. Giuliani, and M. R. Minge. 1981. Finding your best place to live in America. New York: Red Lion Books.

Bruner, J. S. 1957. “On perceptual readiness.” Psychological Review 64: 123-152. doi: $10.1037 / \mathrm{h} 0043805$

Cardy, R. L., and G. H. Dobbins. 1986. “Affect and appraisal accuracy: Liking as an integral dimension in evaluating performance.” Journal of Applied Psychology 71: 672678. doi:10.1037/0021-9010.71.4.672

Chartrand, T. L., van Baaren, R. B., and J. A. Bargh. 2006. "Linking automatic evaluation to mood and information processing style: Consequences for experienced affect, impression formation, and stereotyping”. Journal of Experimental Psychology: General 135: 70-77. doi: 10.1037/0096-3445.135.1.70

Clark, M. S., and A. M. Isen. 1982. Towards understanding the relationship between feeling states and social behavior. In Cognitive Social Psychology, edited by A. Hastorf and A. M. Isen, 73-108. New York: Elsevier.

Clark, M. S., and B. A. Waddell. 1983. "Effects of moods on thoughts about helping, attraction and information acquisition." Social Psychology Quarterly 46: 31-35. doi: $10.2307 / 3033658$

Clore, G. L., Wyer, R. S., Dienes, B. P. A., Gasper, K., Gohm, C., Isbell, L. 2001. Affective feelings as feedback: Some cognitive consequences. In L. L. Martin \& G. L. Clore (Eds.), Theories of mood and cognition: A user's guidebook (pp. 27-62). 
Mahwah, NJ: Erlbaum.

Cohen, J. 1988. Statistical power analysis for the behavioral sciences (2. ed.). Hillsdale, NJ: Erlbaum.

Cuddy, A. J. C., S. T. Fiske, and P. Glick. 2007. “The BIAS Map: Behaviors from intergroup affect and stereotypes." Journal of Personality and Social Psychology 92: 631-648. doi:10.1037/0022-3514.92.4.631

Cuddy, A. J. C., P. Glick, and A. Beninger. 2011. "The dynamics of warmth and competence judgments, and their outcomes in organizations." Research in Organizational Behavior 31: 73-98. doi:10.1016/j.riob.2011.10.004

Davis, R. G. and D. N. Ginthner. 1990. "Correlated color temperature, illuminance level, and the Kruithof curve“. Journal of the Illuminating Engineering Society 19: 2738. doi: 10.1080/00994480.1990.10747937

Dianat, I., Sedghi, A., Bagherzade, J., Jafarabadi, M. A., and A.W. Stedmon. 2013. "Objective and subjective assessments of lighting in a hospital setting: implications for health, safety and performance". Ergonomics 56: 1535-1545. doi: $10.1080 / 00140139.2013 .820845$

Dietl, E., Meurs, J. A., and G. Blickle. 2017. "Do they know how hard I work? Investigating how implicit/explicit achievement orientation, reputation, and political skill affect occupational status.” European Journal of Work and Organizational Psychology 26: 120-132. doi: 10.1080/1359432X.2016.1225040

Dietl, E., Rule, N. O., and G. Blickle. 2018. "Core self-evaluations mediate the association between leaders' facial appearance and their professional success: Adult's 
and children's perceptions." The Leadership Quarterly 29: 476-488. doi:

10.1016/j.leaqua.2018.01.002

Dion, K., Berscheid, E., and E. Walster. 1972." What is beautiful is good". Journal of Personality and Social Psychology 24: 285-290. doi: 10.1037/h0033731

Dobbins, G. H., and J. M. Russell. 1986. "The biasing effects of subordinate likableness on leaders' responses to poor performers: A laboratory and a field study." Personnel Psychology 39: 759-777. doi:10.1111/j.1744-6570.1986.tb00593.x

van Duijnhoven, J., Aarts, M. P. J., Rosemann, A. L. P., and H. S. M. Kort. 2017. Office lighting characteristics determining occupant's satisfaction and health. In M. Kobav (Ed.), Lighting for modern society: proceedings of the Lux Europa 2017 (pp. 384-388). Lighting Engineering Society of Slovenia.

Durante, F., Fiske, S. T., Kervyn, N., Cuddy, A. J., Akande, A. D., Adetoun, B. E., Barlow, F. K. et al. 2013. "Nations' income inequality predicts ambivalence in stereotype content: How societies mind the gap". British Journal of Social Psychology 52: 726-746. doi: 10.1111/bjso.12005

EN, C. (2002). 12464-1. Light and lighting - Lighting of work places - Part 1: indoor work places.

Fiske, S. T., A. J. Cuddy, and P. Glick. 2007. "Universal dimensions of social cognition: Warmth and competence." Trends in Cognitive Sciences 11: 77-83. doi:10.1016/j.tics.2006.11.005

Fiske, S. T., A. J. Cuddy, P. Glick, and J. Xu. 2002. “A model of (often mixed) stereotype content: competence and warmth respectively follow from perceived status 
and competition.” Journal of Personality and Social Psychology 82: 878-902. doi:10.1037//0022-3514.82.6.878

Flynn, J. E. 1992. Lighting-design decisions as interventions in human visual space. In: Environmental Aesthetics: Theory, Research and Applications, New York: Cambridge University Press, pp. 156-179.

Forgas, J. P. 1995. "Mood and judgment: The affect infusion model (AIM)." Psychological Bulletin 117: 39-66. doi:10.1037//0033-2909.117.1.39

Forgas J. P., and J. M. George. 2001. "Affective influences on judgments and behavior in organizations: An information processing perspective." Organizational Behavior and Human Decision Processes 86: 3-34. doi:10.1006/obhd.2001.2971

Fotios, S. 2017. A revised Kruithof graph based on empirical data. Leukos, 13: 3-17. doi:10.1080/15502724.2016.1159137

Greifeneder, R., Bless, H., and M. T. Pham. 2011. "When do people rely on affective and cognitive feelings in judgment? A review." Personality and Social Psychology Review 15:107-141.

Hayes, A. F. 2013. Introduction to mediation, moderation, and conditional process analysis: A regression-based approach. Guilford Press

Illuminating Engineering Society of North America (IESNA). 2013. American national standard practice for office lighting (ANSI/IESNA-RP-1-2012). New York: IESNA.

Imhoff, R., and A. Koch. 2017. "How orthogonal are the big two of social perception? On the curvilinear relation between agency and communion." Perspectives in Psychological Science 12:122-137. doi: 10.1177/1745691616657334 
Isen, A. M. 1987. "Positive affect, cognitive organization, and social behavior." Advances in Experimental Social Psychology 21: 203-253.

Isen, A. M., and R.A. Baron. 1991. „Positive affect as a factor in organizationalbehavior." Research in Organizational Behavior 13: 1-53.

Isen, A. M., K. Daubman, and G. Kowicki. 1987. „Positive affect facilitates creative problem solving." Journal of Personality and Social Psychology 52: 1122-1131. doi:10.1037/0022-3514.52.6.1122

Judd, C. M., James-Hawkins, L., Yzerbyt, V., and Y. Kashima. 2005. "Fundamental dimensions of social judgment: understanding the relations between judgments of competence and warmth". Journal of Personality and Social Psychology 89: 899 -913. $10.1037 / 0022-3514.89 .6 .899$

Juslén, H. T., Wouters, M. C. H. M., and A.D. Tenner. 2007. "Lighting level and productivity: a field study in the electronics industry". Ergonomics 50: 615-624. doi: $10.1080 / 00140130601155001$

Jussim, L. 2012. Social Perception and Social Reality: Why Accuracy Dominates Bias and Self-Fulfilling Prophecy. Oxford University Press.

Knez, I. 1995. "Effects of indoor lighting on mood and cognition.” Journal of Environmental Psychology 15: 39-51. doi:10.1016/0272-4944(95)90013-6

Knez, I., and I. Enmarker. 1998. "Effects of office lighting on mood and cognitive performance and a gender effect in work-related judgment." Environment and Behavior 30: 553-567. doi:10.1177/001391659803000408

Kombeiz, O. 2016. "Turning the spotlight on the role of light and colors in offices: How 
are performance, social interactions, and social perception affected" Electronic published dissertation. University of Hohenheim.

Kombeiz, O., Steidle, A., and E. Dietl. 2017. "View it in a different light: Mediated and moderated effects of dim warm light on collaborative conflict resolution". Journal of Environmental Psychology 51: 270-283. doi: 10.1016/j.jenvp.2017.04.007

Kombeiz, O., and A. Steidle 2018. „Facilitation of creative performance by using blue and red accent lighting in work and learning areas." Ergonomics 61: 456-463. doi:10.1080/00140139.2017.1349940

Küller, R., and T. Laike. 1998. "The impact of flicker from fluorescent lighting on wellbeing, performance and physiological arousal”. Ergonomics, 41: 433-447. doi:10.1080/001401398186928

Küller, R., S. Ballal, T. Laike, B. Mikellides, and G. Tonello. 2006. "The impact of light and colour on psychological mood: a cross-cultural study of indoor work environments." Ergonomics 49: 1496-1507. doi:10.1080/00140130600858142

Langner, O., R. Dotsch, G. Bijlstra, D. H. J. Wigboldus, S. T. Hawk and A. van Knippenberg. 2010. „Presentation and validation of the Radboud Faces Database.” Cognition and Emotion 24: 1377-1388. doi:10.1080/02699930903485076

Leichtfried, V., Mair-Raggautz, M., Schaeffer, V., Hammerer-Lercher, A., Mair, G., Bartenbach, C., and W. Schobersberger. 2015. "Intense illumination in the morning hours improved mood and alertness but not mental performance”. Applied Ergonomics 46: 54-59. doi: 10.1016/j.apergo.2014.07.001

May, J.L., and P.A. Hamilton. 1980. "Effects of musically evoked affect on women's 
interpersonal attraction and perceptual judgments of physical attractiveness of men". Motivation and Emotion 4: 217-228. doi: 10.1007/BF00995420

Mayer, J. D., Gaschke, Y. N., Braverman, D. L., and T. W. Evans. 1992. "Moodcongruent judgment is a general effect". Journal of Personality and Social Psychology 63: 119-132. doi: 10.1037/0022-3514.63.1.119

Nauts, S., O. Langner, I. Huijsmans, R. Vonk, and D. H. J. Wigboldus. 2014. „Forming Impressions of Personality. A Replication and Review of Asch's (1946) Evidence for a Primacy-of-Warmth Effect in Impression Formation.” Social Psychology 45: 153-163. doi:10.1027/a000001

Newsham, G. R., and Veitch, J. A. 2001. "Lighting quality recommendations for VDT offices: A new method of derivation." Lighting Research and Technology. 33: 97-116.

Niedenthal, P. M., and J. B. Halberstadt. 2004. „,Top-down influences in social perception.” European Review of Social Psychology 14: 46-76.

Nitsch J. R. 1976. Die Eigenzustandsskala (EZ-Skala) - Ein Verfahren zur hierarchisch mehrdimensionalen Befindlichkeitsskalierung. [The affective state scale - A method for hierarchically multi-dimensional well-being scaling] In: I.U.J.R. Nitsch (Ed.). Beanspruchung im Sport. Beiträge zur psychologischen Analyse sportlicher Leistungssituationen, 81-102. Bad Homburg, Germany, Limpert.

Park, O. S., H. P. Sims, and S. J. Motowidlo. 1986. Affect in organizations. In The Thinking Organization, edited by H. Sims and D. Gioia, 1-44. San Francisco: Jossey Bass.

Park, J., and Banaji, M. R. 2000. "Mood and heuristics: The influence of happy and sad 
states on sensitivity and bias in stereotyping." Journal of Personality and Social Psychology, 78: 1005-1023. doi: 10.1037//0022-3514.78.6.1005

Richard, F. D., Bond Jr, C. F., and J. J. Stokes-Zoota. 2003. "One hundred years of social psychology quantitatively described.” Review of General Psychology, 7: 331-363. doi: 10.1037/1089-2680.7.4.331

Riggio, R. E., and B. Throckmorton. 1988. "The Relative Effects of Verbal and Nonverbal Behavior, Appearance, and Social Skills on Evaluations Made in Hiring Interviews.” Journal of Applied Social Psychology 18: 331-348. doi:10.1111/j.1559-1816.1988.tb00020.x

Rowe, P. M. 1967. "Order effects in assessment decisions.” Journal of Applied Psychology 51: 13-22. doi:10.1037/h0024346

Rule, N. O., and N. Ambady. 2011. "Face and fortune: Inferences of personality from Managing Partners' faces predict their law firms' financial success". Leadership Quarterly 22, 690-696. doi: 10.1016/j.leaqua.2011.05.009

Rule, N. O., Ambady, N., Adams Jr, R. B., Ozono, H., Nakashima, S., Yoshikawa, S., and M. Watabe. 2010. "Polling the face: prediction and consensus across cultures." Journal of Personality and Social Psychology 98: 1-15. doi: 10.1037/a0017673

Salovey, P., J. D. Mayer, and D. L. Rosenhan. 1991. "Mood and helping: Mood as a motivator of helping and helping as a regulator of mood." Review of Personality and Social Psychology 12: 215- 237.

Sinclair, R. C. 1988. "Mood, categorization, breadth, and performance appraisal: The effects of order of information acquisition and affective state on halo, accuracy, 
information retrieval, and evaluations." Organizational Behavior and Human Decision Processes 42: 22-46. doi:10.1016/0749-5978(88)90018-0

Sona, B., Dietl, E., and A. Steidle 2018. "Recovery in sensory-enriched break environments: Integrating vision, sound and scent into simulated indoor and outdoor environments.” Ergonomics (accepted). doi:10.1080/00140139.2018.1491643

Steidle, A., and L. Werth. 2013. "Freedom from constraints: Darkness and dim illumination promote creativity." Journal of Environmental Psychology 35: 67-80. doi:10.1016/j.jenvp.2013.05.003

Taylor, S. E., and Brown, J. D. 1988. "Illusion and well-being: a social psychological perspective on mental health.” Psychological Bulletin 103: 193-210

Todorov, A., Mandisodza, A. N., Goren, A., and C. C. Hall. 2005. "Inferences of competence from faces predict election outcomes." Science 308: 1623-1626. doi: 10.1126/science.1110589

Tskhay, K. O. and N. O. Rule. 2013. "Accuracy in categorizing perceptually ambiguous groups: A review and meta-analysis." Personality and Social Psychology Review 17: 72-86. doi: 10.1177/1088868312461308

Veitch, J. A., K. E. Charles, G. R. Newsham, C. J. G. Marquardt, and J. Geerts. 2003. Environmental Satisfaction in Open-Plan Environments: 5. Workstation and Physical Condition Effects. Research Report, NRC Institute for Research in Construction, V. 154. doi: $10.4224 / 20378817$

Veitch, J. A., and G. R. Newsham. 1998. "Lighting Quality and Energy-Efficiency Effects on Task Performance, Mood, Health, Satisfaction, and Comfort." Journal of the 
Illuminating Engineering Society 27: 107-129. doi:10.1080/00994480.1998.10748216

Veitch, J. A., and G. R. Newsham. 2000. "Exercised control, lighting choices, and energy use: An office simulation experiment". Journal of Environmental Psychology 20: $219-237$

Veitch, J. A., G. R. Newsham, P. R. Boyce, and C. C. Jones. 2008. "Lighting appraisal, well-being and performance in open-plan offices: A linked mechanisms approach.” Lighting Research and Technology 40: 133-151. doi:10.1177/1477153507086279

Veitch, J. A., M. G. Stokkermans, and G. R. Newsham. 2013. "Linking lighting appraisals to work behaviors." Environment and Behavior 45: 198-214.

doi:10.1177/0013916511420560

de Vries, A., Souman, J. L., de Ruyter, B., Heynderickx, I., and de Kort, Y. A. 2018. „Lighting up the office: The effect of wall luminance on room appraisal, office workers' performance, and subjective alertness.” Building and Environment 142: 534-543. doi:10.1016/j.buildenv.2018.06.046

Watson, D., and Clark, L. A. 1999. The PANAS-X: Manual for the positive and negative affect schedule-expanded form. Ames: The University of Iowa.

Wojciszke, B. 1994. "Multiple meanings of behavior: Construing actions in terms of competence or morality.” Journal of Personality and Social Psychology 67: 222-232. doi: $10.1037 / 0022-3514.67 .2 .222$

Zebrowitz, L. A., and J. M. Montepare. 2008. “Social psychological face perception: Why appearance matters". Social and Personality Psychology Compass 2: 1497-1517. doi: 10.1111/j.1751-9004.2008.00109.x 
Zhu, Y., Yang, M., Yao, Y., Xiong, X., Li, X., Zhou, G., and N. Ma. 2019. "Effects of illuminance and correlated color temperature on daytime cognitive performance, subjective mood, and alertness in healthy adults". Environment and Behavior 51: 199230. doi: $10.1177 / 0013916517738077$ 
Table 1. Characteristics of Lighting Conditions in Study 1.

\begin{tabular}{|c|c|c|c|c|}
\hline & Dim warm & Dim cold & Bright warm & Bright cold \\
\hline Illuminance horizontal & $1501 \mathrm{~lx}$ & $1501 \mathrm{x}$ & $1500 \mathrm{~lx}$ & $1500 \mathrm{~lx}$ \\
\hline Colour temperature horizontal & $2500 \mathrm{~K}$ & $5500 \mathrm{~K}$ & $2500 \mathrm{~K}$ & $5500 \mathrm{~K}$ \\
\hline Illuminance vertical & $501 \mathrm{~lx}$ & $35 \mathrm{~lx}$ & $4101 x$ & $2931 x$ \\
\hline Colour temperature vertical & $2600 \mathrm{k}$ & $5500 \mathrm{k}$ & $2600 \mathrm{k}$ & $5500 \mathrm{k}$ \\
\hline Chromaticity (x) & 0.478 & 0.333 & 0.465 & 0.333 \\
\hline Chromaticity (y) & 0.437 & 0.360 & 0.418 & 0.347 \\
\hline $\mathrm{R}_{\mathrm{a}}$ & 90 & 90 & 90 & 90 \\
\hline
\end{tabular}


Table 2. Descriptive Statistics and Correlations in Study 1.

\begin{tabular}{|c|c|c|c|c|c|c|}
\hline & Variables & Mean $(S D)$ & 1 & 2 & 3 & 4 \\
\hline 1. & Satisfaction with light & $4.34(1.77)$ & .86 & & & \\
\hline 2. & Positive mood & $5.95(1.45)$ & .04 & .89 & & \\
\hline 3. & Judgments of warmth & $3.77(0.70)$ & $.22 * *$ & .06 & .74 & \\
\hline 4. & Judgments of competence & $4.34(0.71)$ & $.23 * *$ & .04 & $.68 * *$ & .71 \\
\hline
\end{tabular}

Notes: $\mathrm{N}=164$. Reliabilities are marked in bold. ${ }^{*} p<.05 ; * * p<.01$. 
Table 3. Hierarchical Regressions on Positive Mood and on Judgments of Warmth and Competence in Study 1.

\begin{tabular}{rccc}
\hline & Positive mood & Warmth & Competence \\
\hline \multicolumn{1}{c}{ Variable } & Model 1 & Model 2 & Model 3 \\
\hline Satisfaction with Light & $\mathrm{b}(\mathrm{SE})$ & $\mathrm{b}(\mathrm{SE})$ & $\mathrm{b}(\mathrm{SE})$ \\
Positive mood & $.03(.06)$ & $.10^{* *}(.03)$ & $.09^{* *}(.03)$ \\
\hline$R^{2}$ & & $.03(.04)$ & $.01(.03)$ \\
\hline
\end{tabular}

Notes: $\mathrm{N}=164$. Values are unstandardized regression coefficients; standard error estimates (SE) are in parentheses. $* p<.05 ; * * p<.01$ 
Table 4. Descriptive Statistics and Correlations in Study 2.

\begin{tabular}{|c|c|c|c|c|c|c|}
\hline & Variables & Mean $(S D)$ & 1 & 2 & 3 & 4 \\
\hline 1. & Satisfaction with light & $5.19(1.27)$ & .90 & & & \\
\hline 2. & Positive mood & $5.81(1.71)$ & $.36 * *$ & .91 & & \\
\hline 3. & Judgments of warmth & $3.86(0.76)$ & $.19 *$ & $.17 *$ & .78 & \\
\hline 4. & Judgments of competence & $4.39(0.71)$ & $.17 *$ & $.14^{\dagger}$ & $.73 * *$ & .82 \\
\hline
\end{tabular}

Notes: $\mathrm{N}=176$. Reliabilities are marked in bold. ${ }^{\dagger} p<.10 ; * p<.05 ; * * p<.01$. 
Table 5. Hierarchical Regressions on Positive Mood and on Judgments of Warmth and Competence in Study 2.

\begin{tabular}{rccc}
\hline & Positive mood & Warmth & Competence \\
\hline \multicolumn{1}{r}{ Variable } & Model 1 & Model 2 & Model 3 \\
\hline Satisfaction with Light & $\mathrm{b}(\mathrm{SE})$ & $\mathrm{b}(\mathrm{SE})$ & $\mathrm{b}(\mathrm{SE})$ \\
Positive mood & $.49^{* *}(.10)$ & $.09^{\dagger}(.05)$ & $.08^{\dagger}(.04)$ \\
\hline$R^{2}$ & & $.05(.04)$ & $.04(.03)$ \\
\hline
\end{tabular}

Notes: $\mathrm{N}=176$. Values are unstandardized regression coefficients; standard error estimates (SE) are in parentheses. ${ }^{\dagger} p<.10 ; * p<.05 ; * * p<.01$ 
Figure 1. The lighting conditions used in the study 1.

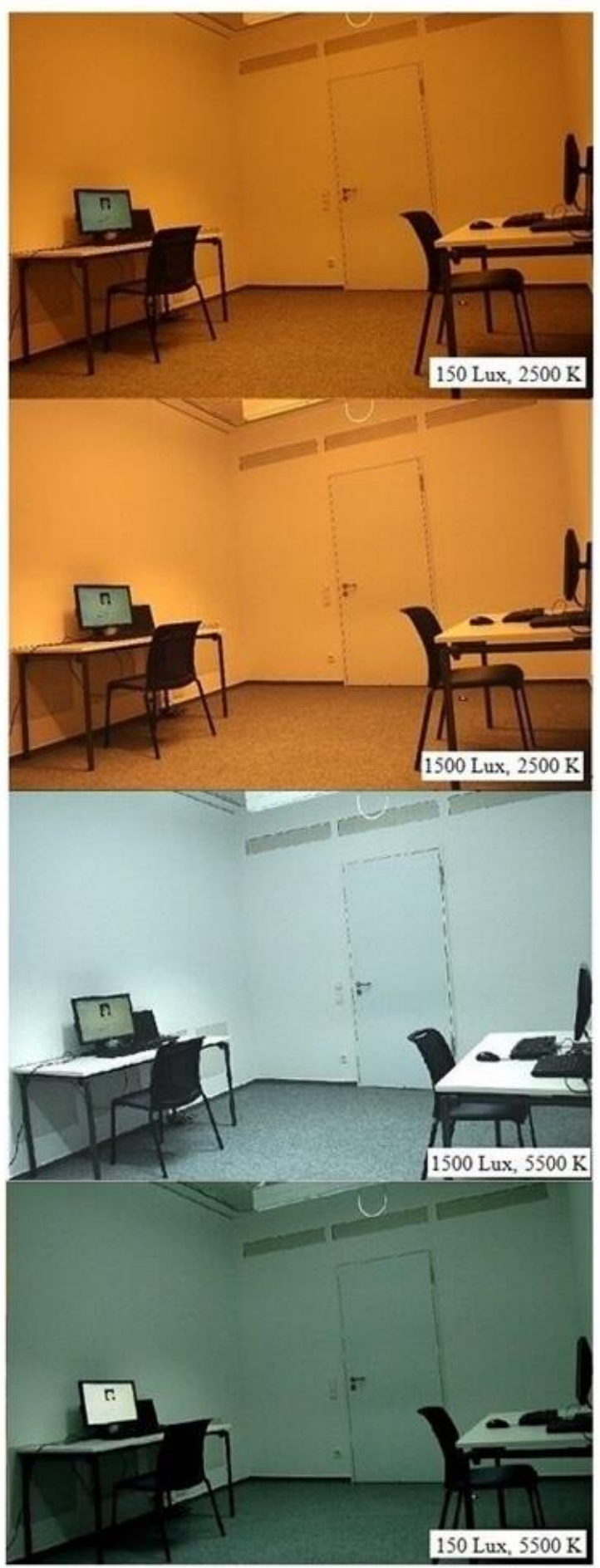

